\title{
Association between Repair Functions and Interlocutor Relationship
}

\author{
TOMOKO TAKEDA \\ University of Oregon
}

\section{Introduction}

Schegloff and his colleagues (1977) proposed the idea that the operation of repair is a communication phenomenon that facilitates the collaborative construction of conversations. Following this proposal, many studies have revealed various aspects of repair in English and other languages, as well as in crosslinguistic studies (e.g., Drew 1997; Fox et al. 1996; Geluykens 1989; Hayashi 1994; Ito 1991; Jefferson 1987; Schegloff 1987, 1992; Weeks 1985; Zahn 1984).

However, the vast majority of previous studies are not concerned with the relationship difference among the interlocutors, and how that difference may affect the repair use. Moreover, despite their in-depth analysis, their results are not presented with statistical support. This study demonstrates operational and functional aspects of repair in two sets of conversations, which differ in terms of the relationship between the participants.

In the following section (section 1), previous studies on repair and those on the linguistic manifestation of participant relationship differences in conversations are discussed. It is followed by the discussion of the data (section 2) and methodology (section 3) of the present study. The results are discussed in the subsequent section (section 4).

\section{Previous Studies}

The previous studies discussed in this section are relevant in the sense that they not only provide basic key definitions and features of repair initially proposed by Schegloff et al. (1977), but show new aspects and directions suggested by later studies following Schegloff et al. (1977).

\subsection{Repair}

Repair is defined as a "communicative phenomenon which helps to sustain social interaction by allowing conversants to mutually handle problems which arise as they communicate" (Schegloff et al. 1977:56). Repair is addressed by conversation analysts in terms of errors and other problems of speaking within 
turn-taking system (Sacks et al. 1974). Repair thus includes but not is limited to corrections. The term "correction," however, is not contingent on the replacement of an "error" or "mistake" in contrast with what is "correct" or limited to "replacement" or "correction" as commonly understood. Therefore, repair is sometimes performed where there is no detectable error, mistake, or fault as in the example below:

$$
\begin{array}{ll}
\text { Bernice: } \quad \rightarrow \text { Dean came up en 'e said I'd like_-' 'Bernice?' } & \rightarrow \quad \text { he said 'I'd like t' take you over tuh Shakey's } \\
& \text { en buy you a beer. }
\end{array}
$$

(Schegloff et al. 1977:363)

Repair is a sequentially organized process. Its typical organization is summarized as follows: (i) initiation (self/other) $\rightarrow$ (ii) repair (self/other) $\rightarrow$ (iii) outcome (success/failure). Schegloff et al. (1977) examine repair in English conversations and propose the following four types of repair in terms of who initiates and who performs the repair: Self-initiated Self-repair, Self-initiated Other-repair, Other-initiated Self-repair, and Other-initiated Other-repair (hereafter S-S, S-O, O-S, and O-O repair, respectively). An example of S-S repair, which is the focus of the present study, is (2) below.

\section{(2) $\quad$ Self-initiated $\rightarrow$ Self-repair}

$1 \quad \mathrm{~N}$ : She was given me a:ll the people that

2 were go:ne this yea:r I mean this

3 quarter y'//know

4 J: Yearh

Now, how do we identify the actual occurrence of repair? One of the key features for the identification is called a repairable. Schegloff et al. (1977) explain that repairables are "the trouble sources" that motivate the initiation of repair and identify the three types of trouble sources: word replacement, person references, and next-speaker selections (pp. 370-372). Zahn (1984) proposes three general types of repairable using the term "problem types." The first problem type is wording, which refers to mispronunciations, verbal slips, ungrammatical expressions, and partial wordings. They result from the speaker's stumbling over pronunciation, wording, or phrasing. The second is error, which is often accompanied by assertions provided by the listener that are not perceived as being correct in terms of their appropriateness, relevance, or truth. Finally, the third type of repairable is ambiguity, which includes memory failure, ambiguity of reference, lack of clarity or comprehensibility, and failure to hear or attend "properly."

In sum, the two key properties identified by previous studies of repair are repair types, which are determined by who initiates and who performs the repair, and repairables, which are what motivates the repair initiation. The following 


\section{Repair Functions and Interlocutor Relationship}

section discusses previous studies on the interactional phenomena associated with different types of participant relationships.

\subsection{Participant Relationship and Interactional Phenomena}

Previous studies that examine conversations between familiars and strangers discuss their observations from various perspectives. Maynard and Zimmerman (1984) discuss conversations between strangers and those between acquaintances in terms of topic choice and management. They found that the acquaintances often initiated topics through another's biographical information (i.e., friendship, interests) and employed people's names and demonstratives without any introduction of these referents. This shows that their topic initiation relies on mutually assumed knowledge. On the other hand, conversations between strangers opened with pre-topical talk to generate typified knowledge of each other's biographical information, and topics in the subsequent sequences tended to be initiated through setting-talk (i.e., participating in the experiment).

Redeker (1990) examined the use of two types of discourse marker, ideational and pragmatic markers, in conversations between friends and those between strangers through film description experiments. Ideational markers mark ideational relations of two discourse units which "entails the speaker's commitment to the existence of that relation in the world the discourse describes" (p. 369). They include simple connectives (i.e., the simple relative pronouns that, who, and which), semantically rich connectives (i.e., the adversative conjunction but, temporal connectives), and other temporal adverbials that specify the event-time referred to in the current utterance in relation to that of the preceding one (i.e., now, then, after that). The pragmatic markers mark rhetorical relations and sequential relations. Two connected discourse units are in a rhetorical relation when the strongest relationship is rather between the utterances themselves. They are in a sequential relation when they "do not have any obvious ideational or rhetorical relation while still being understood as belonging to the same discourse" (p. 369). The pragmatic markers include pragmatically used conjunctions (i.e., (and) so, so (that)) and interjections used as connectives (i.e., utterance-initial uses of oh, all right, utterance-final tags such as okay? or right?). The results from the experiment reveal that the friends use more pragmatic markers than the strangers while the strangers use more ideational markers than the friends.

Shared views among the studies above are that there is an association between the interlocutors' relationship difference in familiarity and their conversational management and that one of the major factors that influence the conversational management is what is perceived as "shared" or "not shared" among the interlocutors.

As reviewed above, those scholars who have investigated characteristics of conversational management have not looked at repair. In a similar manner, interlocutor relationship differences are not of concern among those who have looked at repair mechanisms. The present study, therefore, aims to explore the 
possible interaction between the two phenomena. For both groups of scholars attempting to understand how the conversation participants manage and co-construct their verbal interaction, investigating the relationship between repair and interlocutor relationship would contribute to the further understanding of conversational interaction.

\section{Data}

The data of this study consists of 12 tape-recorded and transcribed face-to-face dyad spontaneous Japanese conversations. Six are between friends, and the other six between strangers. Fourteen of the participants are female and ten are male, of which 19 are so-called "standard Japanese" speakers and five are Kansai-dialect speakers. The length of each transcribed conversation varies from 12 to 22 minutes, totaling approximately 226 minutes. The data is distributed almost equally in length between the two sets of data.

\section{Methodology}

The focus of the present study is two types of S-S repair that occur at First-position. That is, it is a type of repair in which the speaker stops the production of the utterance in some way, and repeats or replaces some part or all of it (S-S repair) in the same turn that contains the repairable (First position) (Hayashi 1994, Schegloff et al. 1977).

First, the sequential organizations of all S-S repairs were examined for the operationalization. The classifications below follow those of Hayashi (1994).

Type 1 Replacement repair: Recycle prior phrase, with a replaced word

Type 2 Addition repair: Recycle prior phrase, with addition of new element(s)

Note that the terms replaced and addition merely refer to the apparent forms in the sequential structure, without any assertion that the speaker meant them to be a replacement or addition. In all the examples from my data, an asterisk $\left(^{*}\right)$ indicates repair initiation and bold-face letters indicate a repaired segment. "STRS" and "FRS" in parentheses at the end of each example refer to "Strangers" conversation" and "Friends' conversation," respectively, and the following number corresponds to the data number.

\section{(3) Replacement repair}

$1 \mathrm{~F}$ :.. mukoo de wa-*,

2 .. nihon de wa nani o-, $3 \mathrm{M}:(0.5) \mathrm{a}$,

4 .. nihon de wa,

5 .. kookoo sotsugyoo shite-,

$6 \mathrm{~F}$ : a sugu kitan desu ka?

(STRS\#4)

$$
\begin{aligned}
& \text { F:... over there-*, } \\
& \text {.. in Japan what did you-, } \\
& \text { M:(0.5)ah, } \\
& \quad \text {.. in Japan, } \\
& \text {.. I graduated a high school and-, } \\
& \text { F: oh you came right after (that)? }
\end{aligned}
$$

In (3), $\mathrm{F}$ formulates a question of what $\mathrm{M}$ was doing in Japan presumably before 
he came to the United States (lines 1-2). In this question, the initial locative NP marked by double particles mukoo de wa 'over there' is recycled with nihon 'Japan' replacing the demonstrative place noun mukoo 'there'.

\section{(4) Addition repair}

$1 \mathrm{~T}$ : ... chuugakkoon toki no,

2 eego no sensee toka ne,

$3 \mathrm{~K}$ : ... shaberenai yo.

$4 \mathrm{~T}:$... shabe*- --

5 zettai shaberenai $[y o]$ ne. (FRS\#1)

\author{
T: ... those English teachers when we \\ were in the middle school, \\ $\mathrm{K}$ : ... cannot speak (English). \\ T: ... cannot spea*- -- \\ definitely cannot speak, right?
}

In (4), $\mathrm{T}$ is making a statement about their middle school English teachers' inability to speak English that is jointly constituted with K. After K's provision of the proposition of the statement, shabere nai yo '(they) cannot speak (English)', at line 3, T stops her reproduction of the same verb from K's previous utterance, shabe-* (line 4), and then continues the reproduction with the addition of an adverb of emphasis, zettai 'definitely' (line 5).

In order to discover the nature of these repairs, all Replacement and Addition repairs were further analyzed in terms of the relationship between the repairable and its repaired segment. However, cases in which the identification of repairable-repaired relationship was obscure are excluded in the discussion of the present study. A total of 64 repairs are classified as Replacement repair and 37 as Addition repair. Each type is further examined and classified into subtypes according to their repairable-repaired relationship.

\section{Results and Discussion}

\subsection{Replacement Repair}

Sixty-four examples of Replacement repair were observed in the data. The comparison between the repairable (a subject element of repair) and its repairing segment revealed four subtypes of Replacement type repair:

Replacement repair-1: from broad/vague to more concrete term

Replacement repair-2: word search (for more appropriate term)

Replacement repair-3: slight semantic coding change

Replacement repair-4: error correction

Example (3) above is an example of Replacement repair-1. The reference of mukoo 'there' in the repairable is vague since there was no anaphoric reference to indicate what mukoo refers to in their previous interaction. On the other hand, the reference of the substituted word, nihon 'Japan', is much more concrete.

The basic format of Replacement repair-2 consists of "Word $1+$ (word search) Hesitation + Word 2," where Word 1 and 2 are semantically similar. ${ }^{1}$ Word search hesitation signals that the speaker is looking for a different word that $\mathrm{s} /$ he thinks is

\footnotetext{
${ }^{1}$ The basic format follows Jefferson's (1974) Error Correction Format.
} 


\section{Tomoko Takeda}

more appropriate or suitable. Clear examples of word search hesitations are to yuuka 'I means (it's) rather', nanteyuun desu ka ne 'how should I put it', and their variants. Less explicit hesitation signals include incomplete stuttered yet recognizable words. See (5) below for an example of this type.

(5) Replacement repair-2: Word search (for more appropriate term)

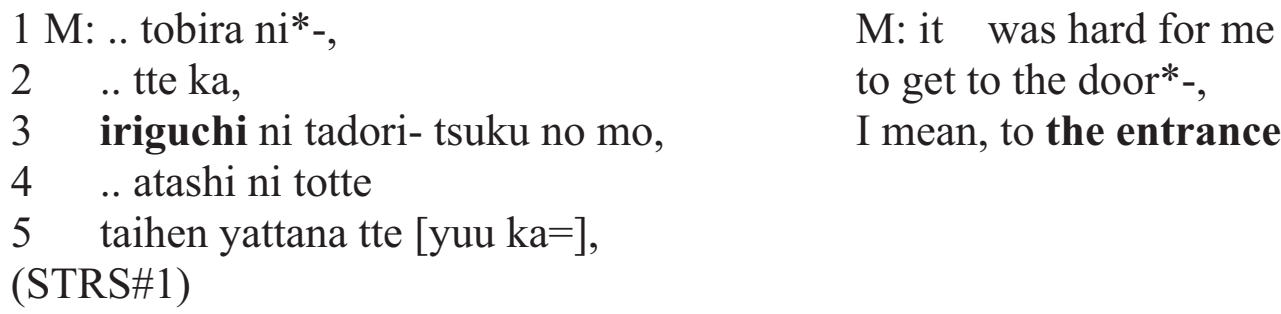

In (5), the repairable is an NP marked by the goal marker $n i$, tobira $n i$ 'to the door', which is followed by hesitation signal tte $k a$ 'I mean'. M then performs a repair, providing the recycled $n i$-marked NP with iriguchi 'the entrance' replacing tobira 'the door'.

Replacement repair-3 involves a slight semantic coding adjustment. That is, the repairable and the replaced word are almost identical or only slightly different semantically. In some cases, the difference between the two is pragmatic.

(6) Replacement repair-3: Slight semantic coding change
$1 \mathrm{~K}$ :.. kizukana*-
2 shiranakatta no,
K:.. (we) didn't realize*-
didn't know that
(FRS\#5)
this (picture) was taken.

In (6), $\mathrm{K}$ is explaining that she and her father were not aware when the picture they are looking at was taken. Note the semantic similarity between the first incomplete word, ${ }^{2}$ kizukana-* '(we) didn't realize' (line 1), and the second word, shiranakatta no '(we) didn't know' (line 2).

The fourth subtype, Replacement repair-4, is the case of error correction. Its basic format consists of "Word $1+$ Hesitation + Word 2," where Word 1 is clearly recognized as an error for its being contextually inappropriate, phonologically misarticulated, or semantically distinctive from Word $2 .^{3}$

\footnotetext{
2 The incomplete formulation, or cut-off marker, in Jefferson's terms, is also considered a hesitation component (Jefferson 1974)

3 The basic format follows Jefferson's (1974) Error Correction Format.
} 
(7) Replacement repair-4: Error correction

\author{
$1 \mathrm{M}: \mathrm{ji}=-*$, \\ 2 .. jii aaru ee ka, \\ 3 .. nan dakke, \\ 4 jii pii ee ya [@@@]. \\ 5 Y:_[@@@]
}

(STRS\#3)

\author{
$\mathrm{M}:$ gee $=$ - $*$ \\ is it GRA? \\ what was it, \\ oh that's GPA [@@] \\ Y: $\quad$ [a@@]
}

In (7) above, realizing that jii aaru ee 'GRA' is not the appropriate word, $\mathrm{M}$ interjects a self-question-type hesitation nan dakke 'what was it?' (line 3), and finally finds an appropriate word and utters jii pii ee ya 'oh, that's GPA'.

Table 1 below shows the distribution of the four subtypes of Replacement repair.

Table 1: Distribution of Four Subtypes of Replacement Repair

\begin{tabular}{lrc}
\hline & Friends & Strangers \\
\hline Type 1-1: Broad/vague to Concrete & 4 & 9 \\
Type 1-2: Word Search & 2 & 7 \\
Type 1-3: Slight semantic coding change & 5 & 10 \\
Type 1-4: Error Correction & 12 & 15 \\
\hline \multicolumn{1}{c}{ Total (64) } & 23 & 41 \\
\hline
\end{tabular}

Analyzing these four subtypes in terms of their functions in interactional management, Replacement repair-1 and -3 , as well as seven instances of Replacement repair- 2 used between strangers, appear to share the same function, namely elaboration. By providing a more concrete or more appropriate choice of word, their utterance becomes more precise and rich with information. They are grouped together and collectively termed "Elaboration repair." The distribution of Elaboration repair in all the instances of Replacement repairs between the two sets of data is presented in Table 2 below.

Table 2: Distribution of Elaboration Repair in Type 1

\begin{tabular}{lcc}
\hline & Friends & Strangers \\
\hline Elaboration repair in Type 1 & 9 & 26 \\
\hline
\end{tabular}

The results in Table 2 indicate a clear distributional difference in Elaboration repair in Type 1 between the two sets of data: the frequency of the use of Elaboration repair among strangers is almost three times higher than that among friends. This indicates that Elaboration repair is clearly strongly associated with the interlocutor relationship of being strangers. 


\section{Tomoko Takeda}

\subsection{Addition Repair}

Addition repair consists of a recycled prior phrase, with addition of a new element(s). Thirty-seven examples of Addition repair were found in the data. Through comparison of the repairable with its repaired segment, two subtypes of added elements were identified: Elaborative addition and Emphatic addition. Twenty-seven examples of Addition repair were identified as Elaborative addition. See (8) below for an example of this type:

(8) Addition repair-1: Elaborative addition

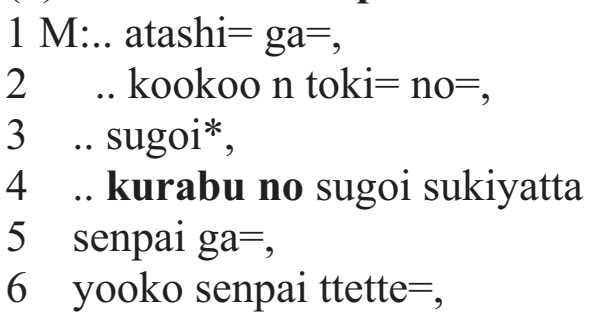

M: when I was in high school

.. there was a senior student whom I really*, ..a senior student of a club whom I really liked, and her name was Yoko and,

(STRS\#1)

In (8), $\mathrm{M}$ adds kurabu no 'of a (school) club' at line 4 before she recycles a previously uttered word, sugoi 'really'. By adding kurabu no 'of a (school) club', the referent senpai 'senior student' and M's relationship with that referent become clearer.

The remaining ten examples of Addition repair involve Emphatic additions. The emphatic added elements include words like zettai 'definitely', mattaku 'not at all', and kekkyoku 'after all'. Example (4) above is one of the examples and reproduced here for convenience as (9).

(9) Addition repair-2: Emphatic addition

$1 \mathrm{~T}$ : ... chuugakkoon toki no,

2 eego no sensee toka ne,

$3 \mathrm{~K}$ : ... shaberenai yo.

$4 \mathrm{~T}$ : ... shabe*.---

5 zettai shaberenai [yo] ne. (FRS\#1)
$\mathrm{T}:$... those English teachers when we were in the middle school, K: ... cannot speak (English).

$\mathrm{T}$ : ... cannot spea*- --

definitely cannot speak, right?

What the added word zettai 'definitely' in (9) at line 5 is doing is to emphasize or strengthen the tone of the speculative statement about junior high school English teachers' inability to speak English.

\subsection{Elaboration Repair vs. Emphatic Repair}

Between the subtypes of Replacement and Addition repair, there is one shared function: elaboration. Therefore, all instances of the elaboration type repair are grouped together. The remaining repair function then is emphatic. The distribution of repairs with elaborative and emphatic functions is presented in Table 3 below. 
Table 3: Distribution of All Elaboration and Emphatic Repair

\begin{tabular}{lcc}
\hline & Friends & Strangers \\
\hline Elaboration repair & 15 & 45 \\
Emphatic repair & 7 & 3 \\
\hline
\end{tabular}

Considering these two functions of repair-elaborative and emphatic-in terms of how they contribute to the way the speaker conveys the message, another aspect of their interactional functions emerges. The Elaboration type repair is oriented toward the facilitation of the listener's comprehension of the message conveyed. In other words, by using S-S repair for elaborative purposes, the speaker facilitates the listener's precise comprehension by creating information-rich and carefully adjusted utterances. On the other hand, the Emphatic type repair is rather affect-oriented. By adding words such as zettai 'definitely', the speaker weaves her affective perspective into her message.

In order to confirm the significance of the distributional difference of these two types of repair functions observed in Table 3, a statistical frequency analysis was further applied to the results. The following is the result of the Fisher Exact Probability Test.

Fisher Exact Probability Test

\begin{tabular}{|c|c|c|}
\hline \multirow{2}{*}{$p$} & One-tailed & 0.01283 \\
\cline { 2 - 3 } & Two-tailed & 0.01283 \\
\hline
\end{tabular}

The calculated probability values $(p)$ indicate that only $1.3 \%$ of the results occurred by chance alone. In other words, $98.7 \%$ of the frequency of the two functions of S-S repair in the data can be accounted for by the difference in the interlocutor's relationship.

What this result suggests is as follows: as far as the two types of S-S repair under investigation are concerned, one function of the S-S repair is Elaboration, which serves to provide fine-tuned or rich information that facilitates the listener's precise comprehension of the message conveyed by the speaker. Repair with this function is much more frequently observed in conversations between strangers. Another function is to weave the speaker's affective perspective into his/her message in production. Although the number of examples is relatively small, it is statistically supported that repair with this function is observed more in conversations between friends.

Here, recall the findings in Redeker's (1990) experimental study on discourse markers. What she found was that friends use more pragmatic markers than strangers whereas strangers use more ideational markers than friends. These findings are consistent with the findings in the present study. That is, strangers tend to use repairs for ideational (propositional) purposes, namely for elaboration of propositional content, while friends tend to use repairs for a pragmatic (affective) purpose, namely for emphasis. This suggests that the relationship differences play a role in various linguistic choices, including specific types of repair and discourse markers. 


\section{Tomoko Takeda}

\section{Conclusion}

This paper presents evidence that certain types of S-S repair exhibit a tendency to be used more for one function in conversations between friends and for another in conversations between strangers. The results of this study therefore suggest that there is an association between functions of certain types of repair and the relationship difference among interlocutors. Additionally, the results of the present study show consistency with Redeker's (1990) experimental study on the use of discourse markers by strangers and by familiars. Recall that one common view shared among previous studies of interaction between familiars and between strangers is that the differences they found are associated with the difference of the interlocutor's perceived sharedness of mutual knowledge. In a similar manner, one possible factor for the high frequency of elaborative function-bearing repair in conversations between strangers is associated with the lack of perceived shared knowledge.

The present study also shows a way in which the data demonstrates how the relationship difference among the interlocutors is associated with their interactional management through linguistic devices.

\section{References}

Drew, Paul. 1997. 'Open' class repair initiators in response to sequential sources of troubles in conversation. Journal of Pragmatics 28:69-101.

Fox, Barbara A., Makoto Hayashi, and Robert Jasperson. 1996. Resources and repair: A cross-linguistic study by syntax and repair. In E. Ochs, E. A. Schegloff, and S. A. Thompson, eds., Interaction and Grammar, 185-237. Cambridge: Cambridge University Press.

Geluykens, Donald. 1989. Referent-tracking and cooperation in conversation: Evidence from repair. In R. Graczyk, B. Music, and C. Wiltshire, eds., Papers from the $25^{\text {th }}$ Annual Regional Meeting of the Chicago Linguistic Society, Part II: Parasession on Language in Context, 65-76.

Hayashi, Makoto. 1994. A comparative analysis of self-repair in English and Japanese. In N. Akatsuka, ed., Japanese and Korean Linguistics, vol. IV. Stanford, CA: CSLI.

Ito, Hiroko. 1991. Taidan bangumi ni okeru "repair." ["Repair" in TV talk shows.] Nihongogaku 6(10):62-74.

Jefferson, Gail. 1974. Error correction as an interactional resource. Language in Society 2:181-199.

Jefferson, Gail. 1987. On exposed and embedded correction in conversation. In G. Button and J. R. E. Lee, eds., Talk and Social Organization, 86-100. Cleveland and Philadelphia: Multilingual Matters.

Maynard, Douglas, and Don H. Zimmerman. 1984. Topic, talk, ritual and social organization of relationship. Social Psychology Quarterly 47(4):301-316. 
McLaughlin, Margaret T., and Nancy E. Rosenstein. 1983. Account sequences in conversations between strangers. Communication Monographs 50:102-125.

Morton, Teru L. 1978. Intimacy and reciprocity of exchange: A comparison of spouses and strangers. Journal of Personality and Social Psychology 36(1): $72-81$.

Redeker, Gisela. 1990. Ideational and pragmatic markers of discourse structure. Journal of Pragmatics 14:267-381.

Sacks, Harvey, Emanuel A. Schegloff, and Gail Jefferson. 1974. A simplest systematics for the organization of turn-taking for conversation. Language 50:696-735.

Schegloff, Emanuel A., Gail Jefferson, and Harvey Sacks. 1977. The preference for self-correction in the organization of repair in conversation. Language 53:361-382.

Schegloff, Emanuel A. 1987. Recycled turn beginnings: A precise repair mechanism in conversation's turn-taking organization. In G. Button and J. R. E. Lee, eds., Talk and Social Organization, 70-85. Cleveland and Philadelphia: Multilingual Matters.

Schegloff, Emanuel A. 1992. Repair after next turn: The last structurally provided defense of intersubjectivity in conversation. The American Journal of Sociology 97(5):1295-1345.

Weeks, Peter A. D. 1985. Error-correction techniques and sequence in instructional settings: Toward a comparative framework. Human Studies 8(3):195-233.

Zahn, Christopher J. 1984. A reexamination of conversational repair. Communication Monographs 51:56-66.

EALL 308 Friendly Hall

University of Oregon

Eugene, OR 97403

ttakeda@darkwing.uoregon.edu 